\title{
Factors associated with early initiation and exclusive breastfeeding practices among mothers of infant's age less than 6 months
}

\begin{abstract}
Back ground: Globally, it is estimated that $60 \%$ of the infant and young child deaths occur due to inappropriate infant feeding practices and infectious disease. Inappropriate breastfeeding patterns are a major contributor of morbidity and mortality in young infants and children in Ethiopia, where about $70.0 \%$ infants are sub-optimally breastfed. Despite this there are limited studies related to factors contributing to it, in Ethiopia and specifically in Gurage zone. The aim of this study was to examine factors associated with Early Initiation of Breast feeding (EIBF) and Exclusive Breastfeeding (EBF) practices among mothers of infant's age less than six months in Gurage zone, SNNPR, Ethiopia.
\end{abstract}

Methods: A cross sectional community based study was conducted in Gurage zone from December 1-31/2016. A multi stage and random sampling technique with proportionate allocation were applied. Data was entered into Epi data 3.1, and analyzed using SPSS version 20:00. Descriptive, bivariate and multivariable logistic regression analysis was employed to identify the association.

Results: A total of 765 mothers were participated in this study. The prevalence of EIBF and $\mathrm{EBF}$ practices were $(47.3 \% ; 95 \% \mathrm{CI}=43.7,50.9)$ and $(49.2 \% ; 95 \% \mathrm{CI}=45.6,52.8)$ respectively. Residence, mother's education, visiting ANC service, delivery at a health facility, vaginal delivery, multiparty and income were positively associated with initiation of breastfeeding within one hour of birth than their counterparts. Likewise, mothers with no formal education, attended ANC, visited PNC, from poorest household index, with small birth order, and primiparous mothers were more likely to practice EBF than their counterparts.

Conclusion: In this study the prevalence of both EIBF and EBF was sub-optimal, and is less than the national and World Health Organization reports. Therefore, designing and implementing specific strategies to enhance the rate of early initiation and exclusive breast feeding practices through community mobilization and empowerment of women is recommended.

Keywords: early initiation of breast feeding, exclusive breast feeding, Ethiopia, children, mothers
Volume 7 Issue 3 - 2017

\author{
Bisrat Zeleke Shiferaw,' Kenzudine Assfa \\ Mossa, ${ }^{2}$ Bosena Tebeje Gashaw ${ }^{3}$ \\ 'Department of Nursing, Wolkite University, Ethiopia \\ ${ }^{2}$ Department of Public health, Wolkite University, Ethiopia \\ ${ }^{3}$ Department of Nursing and Midwifery, Jimma University \\ College of Public Health and Medical Sciences, Ethiopia
}

Correspondence: Bisrat Zeleke Shiferaw, Lecturer, BSc. N MSc. N,Wolkite University, College of Medicine and Health Sciences, Department of Nursing, PO Box 07, Wolkite, Ethiopia, Tel 25I-9|1037686,Email basfendaz@gmail.com

Received: October 18, 2017| Published: November 27, 2017
Abbreviations: ANC, ante natal care; AOR, adjusted odd ratio; COR, crude odd ratio; EBF, exclusive breast feeding; EIBF, early initiation of breast feeding; EDHS, ethiopia demographic and health survey; FMOH, federal ministry of health; HEWs, health extension workers; IYCF, infant and young child feeding; NGOs, non-governmental organizations; PNC, postnatal care; SNNPR, southern nations, nationalities, and peoples region; WHO, world health organization; TBA, traditional birth attendant; RERB, research ethical review board; SES, socio economic status; SPSS, statistical package for social science

\section{Introduction}

Breast milk is superior to any product given to a baby and it is uniquely adapted to baby's needs. Breast milk is important for infants and young children's because it is immediately available, nutritionally balanced, fresh, temperature always correct and constant, economical and provides antibodies (greater immunity to infection). ${ }^{1}$

Optimal breastfeeding, as defined by the World Health Organization (WHO), is the Early Initiation of Breast Feeding (EIBF) within 1 hour of birth, Exclusive Breast Feeding (EBF) for the first six months of life, and continued breastfeeding for up to two years or beyond with appropriate complementary feeding beginning at 6 months; adhering to all three $\mathrm{WHO}$ recommendations are critical to reducing both neonatal and child mortality. ${ }^{2}$

There is consistent and substantial evidence that early, exclusive, and continued breastfeeding through 23 months significantly reduces neonatal and child mortality. Globally, it is estimated that $60 \%$ of the infant and young child deaths occur due to inappropriate infant feeding practices and infectious disease from which two-thirds of these deaths are attributable to sub-optimal breastfeeding practices. ${ }^{3-5}$ Reviews of studies from developing countries showed that infants who are not breastfed are 6 to 10 times more likely to die in the first month of life than infants who are breastfed. It is estimated that suboptimal breastfeeding, especially non-exclusive breastfeeding in the first 6 months of life, results in 1.4 million deaths. $^{6}$

Like in other developing countries inappropriate breastfeeding patterns is a major contributor of morbidity and mortality in young infants and children in Ethiopia. About $70.0 \%$ of infants in the country are sub-optimally breastfed, which is another major contributor to infant mortality rate and $24.0 \%$ of infant death is due to poor breastfeeding practices. ${ }^{7}$ 
In contrast to the "National Strategy for Infant and Young Child Feeding," (IYCF) the guidelines established by world health organization and adopted by the Ethiopian Federal Ministry of Health (FMOH) for optimum breastfeeding; in Ethiopia many new-born are neither breastfed during their first hours of life with colostrum nor exclusively breastfed during their first six months. ${ }^{8}$

According to the Ethiopian Demographic and Health Survey (EDHS) 2011, in South Nation Nationalities and Peoples Region (SNNPR) the Percentage of children who started breastfeeding within 1 hour of birth was 66.5 and the median duration of exclusive breastfeeding was 2.2 months. $^{8}$

Although breastfeeding is one of the components of Primary Health Care in Ethiopia, a wide range of harmful infant feeding practices are documented in the country including the study area even after implementations of infant and young child feeding recommendations. However, there is lack of studies which documented factors associated with timely initiation and exclusive breastfeeding practices in the study area. Therefore, this study aimed to assess factors associated with early initiation and exclusive breastfeeding practices among mothers of infants age less than six months in Gurage zone, Ethiopia

\section{Materials and methods}

A cross sectional community based study was conducted on mothers of infant's age less than 6 months in Gurage Zone from December 1-31/2016. With the objective of assessing factors associated with early initiation and exclusive breastfeeding practices. Gurage Zone is amongst the 13 zones found in the SNNPR; Wolkite the administrative capital of Gurage Zone is located $158 \mathrm{~km}$ away from Addis Ababa and $260 \mathrm{~km}$ from Hawassa the capital of SNNPR. The zone is landed on $155 \mathrm{~km} 2$, between $1,000-3,300 \mathrm{~m}$ above sea level and it is subdivided in to 13 woreda and 2 city administration. According to the zonal statistical office report in 2016 the total population is expected to reach $1,609,908$ of whom $375,109(23.3 \%)$ are women of childbearing age and 83,393 (5.18\%) are infants less than 6 months of age.

The sample size was calculated using a single population proportion formula with confidence interval of $95 \%$ and margin of error 5\%. In the calculation, the prevalence of EIBF and EBF practice was considered to be $52 \%{ }^{8}$ Then, by considering $10 \%$ non-response rate and design effect of 2 , the final sample size was 845 mothers of infants' age less than 6 months.

As to the sampling technique, multi stage sampling technique method was used; where first, 4 woreda and 1 city administration were selected from a total of 13 woredas \& 2 city administration by lottery method, and then the respective kebeles were selected randomly from each woreda. The sampling technique considers probability proportion to population size in each woreda and the numbers of subjects to be included in study from each Kebeles were also calculated using the Proportionate to size allocation technique. House numbers of all the eligible households (i.e. mothers of infant's age less than six months) in the selected kebeles were taken from the community and family profile folder of the respective Health Extension Workers (HEWs) found in the kebele for our sampling frame.

Finally eligible households were selected by lottery method by using house hold numbers from family profile folder. From each household one eligible infant age less than six months with biological mother at the time of survey was selected for the study. In case of the presence of more than one eligible infant and more than one eligible mother per a household the youngest infant and the mother with the youngest infants were selected purposively.
Data were collected using 15 trained data collectors and five supervisors through a pre-tested, structured and interviewer -administered questionnaires. The questionnaire was developed after thorough review of various literatures relevant to the study and prepared in English language. Before the actual data collection, the questionnaire was pre-tested on 5\% (42 subjects) in one of unselected kebele for the study but with similar socio-demographic and economic characteristics. Finally, filled questionnaires were checked for completeness and consistency of the data by the principal investigator on daily basis.

Before conducting the study, the proposal was publicly presented, defended and letter of ethical clearance approval was obtained from Wolkite University, Research Ethical Review Board (RERB). The purpose of the study was explained to the study participants, anonymity and privacy and confidentiality was ensured. Prior to data collection, informed written consent was obtained from the study participants. While obtaining consent from each participant, information related to publishing the study finding were addressed. The respondents' right to refuse or withdraw from participating in the study was also fully acknowledged.

\section{Statistical analysis}

The collected data was cleaned, coded and entered in the computer using Epi data 3.1 and then exported to Statistical Package for Social Sciences (SPSS) version 20:00 for analysis. First, descriptive analysis was carried out for each variable. Bivariate and multivariate logistic regression analyses were conducted to identify determinant factors. Explanatory Variables with a $\mathrm{p}<0.25$ in the bivariate logistic regression were entered into the final multivariate logistic regression analysis to control possible confounding and for further analysis associated with the dependent variable, variables having the $\mathrm{p}<0.05$ were considered as significant. Finally, descriptive summary using frequencies, proportions, and tables were used to present study results.

\section{Results}

\section{Socio demographic characteristics}

A total of 765 mothers having infants of age 0-6 months were considered for the analysis, making a response rate of $90.6 \%$. Most of the mothers were within the age group 20-24 and 25-29 years; 25.0 $\%$ and $27.0 \%$ respectively. More than half $(52.2 \%)$ of the respondents were Muslim by religion followed by Orthodox Christians (36.0\%). Regarding their ethnicity, Gurage 388 (50.7\%); Kebena, 143 (18.7\%); followed by Amhara 127 (16.6\%). The highest proportion of mothers $399(52.1 \%)$ had no formal education and the majority of mothers (79.1\%)had no work and about $25.1 \%$ of mothers belonged to the poorer wealth quintile (Table 1).

\section{Obstetrics and health service related characteristics}

The highest percentage of mothers $(46.1 \%)$ had 4 th or higher order births. More than two third $(72.0 \%)$ of mothers had followed Ante Natal Care (ANC) visit during the period their last pregnancy. Of the total births, more than half $59.0 \%$ took place in home, conducted by Traditional Birth Attendant (TBA) or relatives which account about $56.5 \%$ and the highest proportions of deliveries $(95.9 \%)$ were vaginal (Table 2).

\section{Pattern of breast feeding practices}

Our result showed that the prevalence of EIBF and EBF practices were $47.3 \%(95 \% \mathrm{CI}: 43.7,50.9)$ and $49.2 \%(95 \% \mathrm{CI}: 45.6,52.8)$ respectively. About $408(53.3 \%)$ of the mothers reported as they breastfed more than 10 times per day and nearly one third (31.8\%) 
of them respond that they will increase the frequency of feeding when their infant become sick. Mothers were also asked about way of breastfeeding during mother's sickness, Most of them (65.2\%) continue breast feeding during sickness (Table 3).

Table I Socio-demographic and economic characteristics of the respondents (maternal \& infant), Gurage zone, Ethiopia, December, $2016(n=745)$

\begin{tabular}{|c|c|c|}
\hline Variable & Number & Percent \\
\hline \multicolumn{3}{|c|}{ Mothers age category at birth } \\
\hline$<19$ & 107 & $14.0 \%$ \\
\hline $20-24$ & 191 & $25.0 \%$ \\
\hline $25-29$ & 207 & $27.0 \%$ \\
\hline $30-34$ & 138 & $18.0 \%$ \\
\hline$>=35$ & 122 & $16.0 \%$ \\
\hline \multicolumn{3}{|l|}{ Religion } \\
\hline Muslim & 400 & $52.2 \%$ \\
\hline Orthodox & 274 & $36.0 \%$ \\
\hline Protestant & 64 & $8.3 \%$ \\
\hline Catholic & 17 & $2.2 \%$ \\
\hline Others & 10 & $1.3 \%$ \\
\hline \multicolumn{3}{|l|}{ Ethnicity } \\
\hline Gurage & 388 & $50.7 \%$ \\
\hline Kebena & 143 & $18.7 \%$ \\
\hline Amhara & 127 & $16.6 \%$ \\
\hline Other & 107 & $14.0 \%$ \\
\hline \multicolumn{3}{|l|}{ Mothers education } \\
\hline No formal education & 399 & $52.1 \%$ \\
\hline Primary Education & 220 & $28.8 \%$ \\
\hline Secondary and Above & 146 & $19.1 \%$ \\
\hline \multicolumn{3}{|l|}{ Marital Status } \\
\hline Ever Married & 747 & $97.6 \%$ \\
\hline Singles & 18 & $2.4 \%$ \\
\hline \multicolumn{3}{|l|}{ Mothers occupation } \\
\hline Not Working/ House wife & 605 & $79.1 \%$ \\
\hline Workers & 160 & $20.9 \%$ \\
\hline \multicolumn{3}{|l|}{ Residence } \\
\hline Urban & 254 & $33.2 \%$ \\
\hline Rural & 511 & $66.8 \%$ \\
\hline \multicolumn{3}{|l|}{ Wealth index } \\
\hline Poorest & 154 & $20.1 \%$ \\
\hline Poorer & 192 & $25.1 \%$ \\
\hline Middle & 161 & $21.1 \%$ \\
\hline Richer & $|3|$ & $17.1 \%$ \\
\hline Richest & 127 & $16.6 \%$ \\
\hline \multicolumn{3}{|l|}{ Infants Age Category } \\
\hline $0-I$ months & 191 & $25.0 \%$ \\
\hline $2-3$ months & 313 & $41.0 \%$ \\
\hline 4-6 months & 261 & $34.0 \%$ \\
\hline \multicolumn{3}{|l|}{ Sex of the youngest infant } \\
\hline Male & 379 & $51.1 \%$ \\
\hline Female & 362 & $48.9 \%$ \\
\hline
\end{tabular}

Table 2 Distribution of respondents by obstetrics and health service related variables, Gurage Zone, Ethiopia, December, $2016(n=745)$

\begin{tabular}{lll}
\hline Variables & Number & Percent \\
\hline Live birth & & \\
I-4 live birth & $59 I$ & $77.3 \%$ \\
>=5 live birth & 174 & $22.7 \%$ \\
Birth order & & \\
Ist & 159 & $20.8 \%$ \\
2nd-3rd & 253 & $33.1 . \%$ \\
4th and above & 353 & $46.1 \%$ \\
ANC visit & & \\
Yes & $55 I$ & $72.0 \%$ \\
No & 214 & $28.0 \%$ \\
\hline
\end{tabular}

Table Continued...

\begin{tabular}{lll}
\hline Variables & Number & Percent \\
\hline $\begin{array}{ll}\text { Place of delivery } \\
\text { Home }\end{array}$ & 452 & $59.0 \%$ \\
$\begin{array}{l}\text { Health facility } \\
\text { Mode of delivery }\end{array}$ & 313 & $41.0 \%$ \\
$\begin{array}{l}\text { Vaginal delivery } \\
\text { Cesarean section }\end{array}$ & 734 & $95.9 \%$ \\
$\begin{array}{l}\text { Delivery/ birth attendant } \\
\text { Health professionals }\end{array}$ & 31 & $4.1 \%$ \\
$\begin{array}{l}\text { TBA/Relatives } \\
\text { Postnatal visit }\end{array}$ & 333 & $43.5 \%$ \\
Yes & 432 & $56.5 \%$ \\
No & 205 & $26.8 \%$ \\
\hline
\end{tabular}

$\mathrm{ANC}=$ Ante Natal care, $\mathrm{TBA}=$ Traditional Birth Attendant

Table 3 Patterns of breast feeding practice among respondents, Gurage Zone, Ethiopia, December, $2016(n=745)$

\begin{tabular}{|c|c|c|}
\hline Variables & Number & Percent \\
\hline \multicolumn{3}{|c|}{ Initiation of breastfeeding } \\
\hline Within one hour & 362 & $47.3 \%$ \\
\hline After one hour & 380 & $49.7 \%$ \\
\hline Don't know & 23 & $3.0 \%$ \\
\hline \multicolumn{3}{|c|}{ Frequency of breastfeeding } \\
\hline$>10$ times & 408 & $53.3 \%$ \\
\hline$<10$ times & 321 & $42.0 \%$ \\
\hline Don't know & 36 & $4.7 \%$ \\
\hline \multicolumn{3}{|c|}{ Frequency of maternal feeding } \\
\hline Less than the usual & 76 & $10.0 \%$ \\
\hline About the same & 210 & $27.4 \%$ \\
\hline More than the usual & 448 & $58.5 . \%$ \\
\hline Don't know & 31 & $4.1 \%$ \\
\hline \multicolumn{3}{|c|}{ Frequency of breast feeding during Child illness } \\
\hline Less than the usual & 209 & 27.3. \% \\
\hline About the same & 292 & $38.2 \%$ \\
\hline More than the usual & 244 & $31.8 \%$ \\
\hline Don't know & 20 & $2.7 . \%$ \\
\hline \multicolumn{3}{|c|}{ Breastfeeding during mother's sickness } \\
\hline Stop breastfeeding & 92 & $12.0 \%$ \\
\hline Continue breastfeeding & 499 & $65.2 \%$ \\
\hline Decrease breastfeeding & 145 & $19.0 \%$ \\
\hline Don't know & 29 & $3.8 \%$ \\
\hline \multicolumn{3}{|l|}{ Exclusive breastfeeding } \\
\hline Yes & 376 & $49.2 \%$ \\
\hline No & 389 & $50.8 \%$ \\
\hline
\end{tabular}

\section{Factors associated with EIBF practice}

The multivariate analysis results show that residence, maternal education, household wealth index, birth order, ANC visit, place of delivery and mode of delivery were the determinants of EIBF after adjusted with other covariates. Mothers who lived in urban areas of the zone were more likely to begin breastfeeding early as compared to their rural counterpart AOR 1.26, 95\% CI= 1.04, 1.55. Mothers who attended formal education were found to be 1.2 times more likely to practice EIBF than mothers with no formal education AOR 1.21, 95\% $\mathrm{CI}=1.05,1.26$. Concerning household wealth index, mothers from the poorest households were less likely to initiate breastfeeding early as compared to mothers from poorer $\mathrm{AOR}=1.31,95 \% \mathrm{CI}=1.16,1.93$; middle $\mathrm{AOR}=1.42,95 \% \mathrm{CI}=1.16,2.45$; richer $\mathrm{AOR}=2.00,95 \%$ $\mathrm{CI}=1.47,2.96$ and richest $\mathrm{AOR}=1.32,95 \% \mathrm{CI}=1.02,3.09$.

The odds of EIBF among mothers with 2nd -3rd and 4th and above birth order were 1.5 and 1.3 times higher as compared to mothers who 
had 1st birth order with a confidence interval of AOR 1. 52; $95 \% \mathrm{CI}$ 1.08, 2. 84 and AOR 1.34; 95\% CI 1.15, 2.72 respectively. Mothers who visited ANC during their course of pregnancy were found to be 1.5 times more likely to initiate breastfeeding within 1 hour of birth as compared to their counterparts AOR 1.50; 95\% CI 1.05, 2. 08. Likewise, mothers who delivered in a health facility were 1.5 times more likely to initiate breastfeeding within 1 hour of birth as compared to mothers who delivered at home AOR 1.50; 95\% CI 1.12, 1.89. Furthermore, the odds of EIBF was 3 times higher for mothers who had vaginal delivery as compared to mothers who had caesarean section AOR 2.50; 95\% CI 2.14, 4.36 (Table 4).

Table 4 Predictors of early initiation and exclusive breast feeding practice, Gurage zone, Ethiopia, December, $2016(n=745)$

\begin{tabular}{|c|c|c|c|c|}
\hline \multirow{2}{*}{ Variables } & \multicolumn{2}{|c|}{ Initiation of BF within I h of birth } & \multicolumn{2}{|c|}{ EBF practice } \\
\hline & COR (95\% CI) & AOR (95\% Cl) & COR $(95 \% \mathrm{CI})$ & AOR (95\% CI) \\
\hline \multicolumn{5}{|c|}{ Mothers age category at birth } \\
\hline$<19$ & 1.00 & 1.00 & & \\
\hline $20-24$ & $1.26(1.21,1.69)$ & $0.75(0.69,1.25)$ & $2.40(2.53,5.7 I)$ & I.26(0.96,4.96) \\
\hline $25-29$ & $\mathrm{I} .50(\mathrm{I} .20, \mathrm{I} .84)$ & I.32 (0.88, I.76) & I.23(0.77,2.92) & I.13(0.67,2.26) \\
\hline $30-34$ & $0.83(0.72, \mathrm{I} .93)$ & $0.68(0.55, \mathrm{I} .22)$ & $1.24(1.10,2.01)$ & I.I I $(0.98, I .70)$ \\
\hline$>=35$ & I. 23 (I. II, I.67) & $0.92(0.42,1.18)$ & $0.8 \mathrm{I}(.05 \mathrm{I}, 0.12)$ & $0.42(0.16, I .5 I)$ \\
\hline \multicolumn{5}{|l|}{ Mothers education } \\
\hline No formal Education & 1.00 & \multicolumn{3}{|c|}{ I.77 (I.57, 2.69) I.42 (I.I6, I.82) ** } \\
\hline Formal Education & $\mathrm{I} .45(\mathrm{I} .29, \mathrm{I} .57)$ & $\mathrm{I} .2 \mathrm{I}(\mathrm{I} .05, \mathrm{I} .26)^{*}$ & 1.00 & \\
\hline \multicolumn{5}{|l|}{ Currently married } \\
\hline No & 1.00 & 1.00 & & \\
\hline Yes & I.3I (I.II, 2.05) & $0.8 \mathrm{I}(0.98, \mathrm{I} .70)^{*}$ & $2.25(1.95,3.91)$ & I.7I $(I .12,2.70)^{*}$ \\
\hline \multicolumn{5}{|l|}{ Mothers occupation } \\
\hline Not Working/ House wife & 1.00 & 1.00 & & \\
\hline Workers & I.2I $(0.8 \mathrm{I}, 2.13)$ & $\mathrm{I} .04(0.87, \mathrm{I} .26)$ & $0.57(0.34,0.72)^{*}$ & $0.45(0.18,0.67)$ \\
\hline \multicolumn{5}{|l|}{ Household wealth index } \\
\hline Poorest & 1.00 & $1.93(1.58,2.89) \quad 2$ & I $(1.76,3.95)$ & \\
\hline Poorer & $2.15(1.80,2.85)^{* *}$ & $1.31(1.16,1.93)^{*}$ & $1.30(0.96,2.17)$ & $1.81(1.05,3.10)^{*}$ \\
\hline Middle & $2.21(2.02,3.15)^{*}$ & $1.42(1.16,2.45)^{*}$ & $0.83(0.69,1.67)$ & I. 35 (I.0I, 2.11$)$ \\
\hline Richer & $2.30(1.82,2.89)^{*}$ & $2.00(1.47,2.96)^{*}$ & $0.84(0.96,2.17)$ & $\mathrm{I} .14(\mathrm{I} .52,3.50)$ \\
\hline Richest & I. $94(2.22,3.83)^{*}$ & I.32 (I.02, 3.09)* & 1.00 & \\
\hline \multicolumn{5}{|l|}{ Residence } \\
\hline Rural & 1.00 & 1.00 & & \\
\hline Urban & $1.50(1.43,1.97)^{*}$ & $1.26(1.04,1.55)^{*}$ & $0.45(0.29,0.62)^{* *}$ & $0.52(0.19,0.96)^{*}$ \\
\hline \multicolumn{5}{|l|}{ Infants Age Category } \\
\hline 4-6 months & 1.00 & 1.00 & & \\
\hline 2-3 months & I.22 $(0.95,4.07)$ & $0.74(0.54,3.91)$ & $2.20(1.6,3.05) *$ & $\mathrm{I} .5 \mathrm{I}(\mathrm{I} .08,3.46)^{*}$ \\
\hline $0-1$ months & $2.30(1.74,7.36)$ & $1.25(0.75,5.17)$ & $4.32(3.40,7.90)^{*}$ & $3.50(3.11,6.12)^{*}$ \\
\hline \multicolumn{5}{|l|}{ Sex of the child } \\
\hline Female & 1.00 & 1.00 & & \\
\hline Male & I.2I $(1.05,2.02)$ & $0.89(0.7 \mathrm{I}, \mathrm{I} .82)$ & $2.25(1.27,3.73)$ & $\mathrm{I} .82(0.8 \mathrm{I}, 2.52)$ \\
\hline \multicolumn{5}{|l|}{ Birth order } \\
\hline lst & 1.00 & \multicolumn{3}{|c|}{$4.38(0.86, I 1.10) 2.12(2.48,9.65)^{*}$} \\
\hline 2nd -3rd & $2.31(1.52,3.53)$ & I. $52(1.08,2.84)^{*}$ & \multicolumn{2}{|c|}{$2.80(1.47,8.98) \quad$ I. 2 I $(1.02,5.45)^{*}$} \\
\hline 4th and above & I. $10(1.98,3.52)$ & $1.34(\mathrm{I} .15,2.72) *$ & \multicolumn{2}{|c|}{1.00} \\
\hline \multicolumn{5}{|l|}{ ANC visit } \\
\hline No & 1.00 & \multicolumn{3}{|l|}{1.00} \\
\hline Yes & $2.36(1.55,3.74)^{*}$ & $1.50(1.05,2.08)^{* *}$ & \multicolumn{2}{|c|}{ I.87 (I.5I, 2.58$)^{*}$ I.46 (I.06, I.98)* } \\
\hline \multicolumn{5}{|l|}{ Place of delivery } \\
\hline Home & 1.00 & 1.00 & & \\
\hline Health facility & $\mathrm{I} .84(\mathrm{I} .56,2.86)^{*}$ & $1.50(1.12,1.89)^{*}$ & $2.43(1.85,3.7$ & $73)^{*}$ I.32 $(0.34,4.25)$ \\
\hline Mode of delivery & & & & \\
\hline Caesarian section & 1.00 & 1.00 & & \\
\hline Vaginal delivery & $1.98(I .27,2.7 \mathrm{I})^{*}$ & $2.50(2.14,4.36)^{*}$ & $2.55(I .75,3.4$ & $.42) * 1.60(0.93,2.80)$ \\
\hline Delivery/ birth attendar & & & & \\
\hline TBA & 1.00 & 1.00 & & \\
\hline Health professionals & I.2I $(1.78,3.85)^{*}$ & I.54 $(0.89,2.55)$ & $3.0 \mathrm{I}(2.52,5 . \mathrm{I}$ & II $)^{*} \mathrm{I} .25(0.95,2.55)$ \\
\hline Postnatal visit & & & & \\
\hline No & 1.00 & 1.00 & & \\
\hline Yes & $\mathrm{I} .49(\mathrm{I} .6 \mathrm{I}, 2.85)^{*}$ & I.0I $(0.76, \mathrm{I} .84)$ & $4.4 I(3.4 I, 6.52$ & $52)^{*} 2.51(1.45,4.94)^{*}$ \\
\hline
\end{tabular}

ANC $=$ Ante Natal care, $\mathrm{TBA}=$ Traditional Birth Attendant, $\mathrm{COR}=$ Crude Odd Ratio, $\mathrm{AOR}=$ Adjusted Odd Ratio

**Indicates a P-value of $<0.00 \mathrm{I}$ and *Indicates a P-value of $<0.05$ 


\section{Factors associated with EBF practice}

Concerning the practice of exclusive breast feeding the multivariate logistic regression analysis shows that; mothers education, household wealth index, infants age category, birth order, ANC visit and Post Natal Care (PNC) visit were found to be significantly associated with exclusive breast feeding practice. Mothers who had not attained formal education were 1.4 times more likely to exclusively breast feed their infant as compared to their counterpart, AOR $1.42 ; 95 \% \mathrm{CI}$ $1.16,1.82$. Regarding household wealth index, compared to mothers from the richest households; mothers from richer, middle, poorer and poorest households were more likely to breast feed exclusively; Richer AOR $=1.14,95 \% \mathrm{CI}=1.52,3.50$; Middle AOR $=1.35,95 \%$ $\mathrm{CI}=1$. 01, 2.11; Poorer $\mathrm{AOR}=1.81,95 \% \mathrm{CI}=1.05,3.10$; and poorest $\mathrm{AOR}=2.51,95 \% \mathrm{CI}=1.76,3.95$.

Infants of age category 4-6 months were found less likely to be breast feed exclusively than infants of age group 2-3 months $\mathrm{AOR}=1.51,95 \% \mathrm{CI}=1.08,3.46$; and $0-1$ months $\mathrm{AOR}=3.50,95 \%$ $\mathrm{CI}=3.11,6.12$. Similarly, mothers with 4 th and above birth order had lower odds for exclusively breastfeeding their infants as compared to mothers who had 2nd-3rd AOR=1.21, 95\% CI=1.02, 5.45 and $1 \mathrm{st}$ birth order $\mathrm{AOR}=2.12,95 \% \mathrm{CI}=2.48,9.65$. Furthermore, mothers who visited ANC and those who attended PNC service were found to be significantly more likely to breastfeed exclusively their infants; $\mathrm{AOR}=1.46,95 \% \mathrm{CI}=1.06,1.98$ and $\mathrm{AOR}=2.51,95 \% \mathrm{CI}=1.45,4.94$ (Table 4).

\section{Discussion}

The finding of the study shows that the prevalence of EIBF was $47.3 \%$, which is considered under fair category according to WHO classification for the prevalence of EIBF. ${ }^{9}$ It is nearly consistent with the studies conducted in some African countries such as Ghana (46\%) and Gambia (48\%) but higher than in Pakistan (29\%), India (24.5\%) and China $(23.2 \%) ;{ }^{10}$ the difference might be attributed to cultural difference, beliefs and myth on colostrums and EIBF between these countries.

While controlling with other covariates, this study revealed a statistically significant associations between EIBF and some of the socio-economic variables including; household wealth index, maternal education and residence. The result indicates that mothers from wealthier households were more likely to commence breastfeeding early as compared to mothers from poorest household. Similar results have been observed in the previous studies which revealed that richer household wealth was associated with increased likelihood of EIBF. ${ }^{11-13}$

Similarly our findings showed that maternal education was significantly associated with EIBF, which is in line with a study done in Nepa ${ }^{14}$ which indicates that maternal education had significant effect on EIBF. However, it is contrast with a study done in Nigeria where EIBF was not associated with maternal educational level. ${ }^{11}$ This could be possibly due to differences in the sample size.

In line with the finding of study conducted in Nigeria EIBF was found to be practiced more among urban mothers than their counterparts. Lower levels of incomes, inaccessibility of access health care facilities and information might be the possible explanation for lower practice of EIBF among mothers in rural areas. ${ }^{11,15}$

In contrast to studies done in Nigeria and Nepal ${ }^{11,14}$ our finding showed that mothers' occupational status was not significantly associated with EIBF. Difference in the measure of educational status scale might be the possible explanation for this. The association between breastfeeding and Socio Economic Status (SES) are complex as differing aspects of SES may be associated with knowledge, attitudes, experiences, and beliefs leading a woman to a particular infant feeding practice. ${ }^{16}$ A more detailed research might attempt to measure all aspects of SES to discern which dimensions play are the most important roles with regards to EIBF in Ethiopia.

Among the measure of obstetrics and health service related variables; ANC follow up, birth order, place of delivery and mode of delivery were found to have significant association with EIBF. Mothers who attend ANC service during their period of pregnancy were found to be more likely to initiate breastfeeding within 1 hour of birth. This finding is similar with a study done in Ethiopia. ${ }^{17}$ This could be due to better exposure to information or increased awareness about EIBF held by mothers who visited ANC service when compared to those who had not visited ANC. Early initiation of breast feeding was also found to be associated with the birth order. Other studies also reported similar findings, ${ }^{11,18}$ in which previous breastfeeding experience and the number of children was positively associated with EIBF.

The multivariate regression analysis of this study showed that the odds of mothers initiating breastfeeding within 1 hour of birth were higher among mothers who delivered in health facilities than mothers who delivered at home. This finding is comparable with the study done in Nigeria; ${ }^{11}$ Support and assistant from trained health care providers from the health facilities in the process of achieving EIBF could be the possible explanation for the difference between the two groups.

Similarly initiation of breastfeeding within 1 hour of birth was higher among mothers who had vaginal delivery as compared to mothers who had caesarean section and this finding is comparable other studies ${ }^{11,19}$. The possible explanation for a lower practice of EIBF among mothers who delivered by caesarean section could be related with the caesarean section procedure, like the pain from the surgery site, the effect of anesthesia, and the fatigue from a difficult labor. ${ }^{20,21}$

Regarding practice of EBF our study finding showed that the prevalence rate of EBF was $49.2 \%$ which is lower than EDHS report and the WHO recommendations 2011.8, 9 However, the finding is comparable with other study findings in Tanzania, ${ }^{22}$ Uganda, ${ }^{23}$ Kenya, ${ }^{24}$ and Brazil. ${ }^{25}$

Like in many other developing countries, the practice of mother giving water or tea to their children in addition to the breast milk was common. ${ }^{24,26}$ Most of the mothers provided their children water because they thought that the milk was insufficient: breast milk seen primarily as food and water is required to satisfy the needs of the child which was probably due to misconception of mothers. ${ }^{26-29}$

The use of pre-lacteal feeding is another current deterrent impeding the promotion of EBF in many developing countries ${ }^{23,30}$ including in Ethiopia as is evidenced by the ongoing practice of feeding other than breast milk within the first three days of newborn. The explanations given in the current study was that mothers believe that they need to wait until the milk started flowing, secondly giving liquid will clean the baby's throat and it has been a long standing tradition. ${ }^{23}$

The multivariate logistic regression analysis of this study shows that; among socio-demographic variables mothers education, household wealth index and infants age category were found as a predictors of EBF practice. Likewise, from the measure of obstetrics and health service related variables; birth order, ANC and PNC visit were found to be significantly associated with exclusive breast feeding practice. 
In this study maternal education level showed a negative association with EBF practice; educated mothers were found to be less likely to breastfeed exclusively than their counter part. Higher opportunity for employment and inadequate maternity leave among educated mothers could decrease their contact with their infant and will leads to a compromised EBF practice. Better information and access about human milk substitutes could also be the other possible explanation for this. Similar findings were also found in other developing countries but it contradict with the study findings in developed countries like USA ${ }^{31}$ where higher maternal education is related to higher rates of $\mathrm{EBF}$.

The study revealed that the practice of EBF had inverse association with household wealth index. Mothers with poor and middle household wealth index were found to be more likely to breast feed exclusively their infant than richest household wealth index. This finding is consistence with other study done in Ethiopia and South Africa: ${ }^{17,26}$ where mothers with less income practiced breastfeeding more likely than with higher income. The economical scarcity to afford nonhuman milk for their infants might be one of the explanations which make EBF to be practiced more among poor wealth index family than the richest one.

Likewise, our study finding showed that the rate of EBF decreased significantly as the age of the child increases. It is consistent with the reports from Nigeria, and India. ${ }^{30,32}$ Similarly, the study also found that birth order had significant association with EBF practice; mothers with 4th and above birth order had lower odds for exclusively breastfeeding their infants as compared to mothers who had 2nd-3rd and 1st birth order. Short birth interval/spacing between children's could probably explain this.

Furthermore, mothers who visited ANC and attend PNC follow up were found more likely to exclusively breastfeed their infants than their counterparts. The finding is consistent with similar studies done in India and Nigeria. ${ }^{33,34}$ The counseling service provided about appropriate infant and young child feeding practice by the health professionals from maternal and child health clinic might be the possible explanation for this.

Generally, it is evidenced that factors that interact with the protective effect of breastfeeding practice included environmental, cultural and economic characteristics. In developing countries like Ethiopia with a population of high infant mortality, high illiteracy, poor sanitation facilities, poor nutritional status, and generally low economic status; the protective effect of breastfeeding is most important ${ }^{25}$. As the study is conducted at zonal level it has strength of being a representative study. However, recall bias on initiation of breast feeding could be one of its limitations and also cause and effect relationship cannot be ascertained in this study as it is a cross-sectional.

\section{Conclusion}

Overall, this study has shown that the prevalence of both initiation of breast- feeding within 1 hour of birth $(47.3 \%)$ and the practice of exclusive breast feeding (49.2\%), among mothers found in Gurage zone is not optimal; and is less than the national report which is $52.0 \%{ }^{8}$

Generally, our finding revealed that urban mothers, educated mothers, mothers who visited ANC service, multiparous mothers, mothers with vaginal deliveries and mothers from high income family were found more likely to initiate breast- feeding within 1 hour of birth to their new-born than their counterparts and adjusted with other covariates. Whereas, concerning EBF in the zone, the finding noted that a number of child and maternal attributes were found to affect the rate its practice. The practice of EBF were found low among; educated mothers, mothers from higher income family, mothers with higher birth order and mothers who did not attend ANC and PNC visit.

Therefore, as a whole in the study area, if optimal breastfeeding is going to be practiced, appropriately the zonal health department in collaboration with other stakeholders like Non-Governmental Organizations (NGOs) and Wolkite University community service directorate should look into and work on those factors that determine the practice of EIBF\& EBF and should give more emphasis on designing and implementing different health Information, Education and Communication programs which focuses on promotion of EIBF\& EBF through empowerment of women. The HEWs found in the zone should work more on mobilizing the community about the importance of EIBF\& EBF their infant for the first six months. Promotional activities that aimed on improving the rate of ANC and PNC followup should also be given more emphasis by the HEWs during their home to home visit.

\section{Acknowledgments}

We would like to thank Wolkite University for funding this research project (WKU/RCUIL/R005). Our gratitude goes to Gurage Zone health department, supervisors, data collectors, respondents who participated in this study. Finally we thank for language editing Mr. Mark Demos (American Peas corps volunteer, in Ethiopia) and Mr. Sefu Bogale (English language teacher in Wolkite University, Ethiopia).

\section{Competing interests}

The authors declare that they have no any financial or non-financial competing interests.

\section{Ethical approval and consent to participate}

Before conducting the study, the proposal was presented, defended and letter of ethical clearance approval was obtained from Wolkite University, Research Ethical Review Board (RERB); (Ref No.WKU/ RCSUIL/RERB/005/16). The purpose of the study was explained to the study participants and privacy and confidentiality was ensured. Prior to data collection, informed written consent was obtained from the study participants. The respondents' right to refuse or withdraw from participating in the study was fully acknowledged.

\section{Authors contributions}

Bisrat Zeleke: The principal investigator designed the study, collect, analyses and interprets the data, and also drafted the manuscript.

Kenzudine Assfa: Equally participated in conceptualization of the study, design, analyses and interpretation of results as well as drafting and review of the manuscript.

Bosena Tebeje: Drafting and critical reviewing the manuscript. All authors read and approved the final manuscript.

\section{References}

1. Academy for Educational Development: Feeding New Born and InfantsBreastfeedinglinkages: Anand's guide to child care. 2006.

2. World Health Organization (WHO) Global Strategy for Infant and Young Child Feeding:The Optimal Duration of Exclusive Breastfeeding Med. 2006;105:40-44.

3. Black RE. Maternal and Child Under nutrition and Overweight in LowIncome and Middle-Income Countries: The Lancet. 2013;382:427-451. 
4. Bhutta ZA. Evidence-Based Interventions for Improvement of Maternal and Child Nutrition: What Can be Done at What Cost? :The Lancet. 2013;382(9890):452-477.

5. Geneva. World Health Organization (WHO):Global Strategy for Infant and Young Child Feeding: A joint WHO/UNICEF statement. Switzerland. 2003;3-5.

6. World Health Organization (WHO). Infant and young child feeding:Model chapter for textbooks for medical students and allied health professionals. 2009;1:99

7. Federal Ministry of Health Ethiopia (FMOH): Plan of action of the National Control of Diarrhea Diseases Programme:(1990-1992).

8. Central Statistical Agency, Ethiopia and ORC Macro: Ethiopia Demographic and Health Survey(EDHS). Addis Ababa, Ethiopia and Calverton, Maryland, USA: Central Statistical Agency and ORC Macro. 2011.

9. Infant and Young Child Feeding: A tool for assessing national practices, policies and programme: 2010. [http://www.who.int/nutrition/ publications/inf_assess_nnpp_toc_eng.pdf].

10. Arun Gupta. Initiative WBT: The State of Breastfeeding in 33 Countries. India: BPNI / IBFAN Asia. 2010.

11. Anselm S Berde, Siddika Songül Yalcin. Determinants of early initiation of breastfeeding in Nigeria:a population- based study using the 2013 demographic and health survey data. BMC pregnancy and child health. 2013;6:16-32

12. Mihrshahi S, Kabir I, Roy SK, et al. Determinants of infant and young child feeding practices in Bangladesh: secondary data analysis of Demographic and Health Survey 2004. Food Nutr Bull .2010;31:295-313.

13. Yahya WB, Adebayo SB. Modelling the Trend and Determinants of Breastfeeding Initiation in Nigeria. Child Dev Res. 2013;1-9.

14. Adhikari M, Khanal V, Karkee R, et al. Factors associated with EIBF among Nepalese mothers: further analysis of Nepal Demographic and Health Survey, 2011. Int Breastfeed. 2014;9(1):1-21.

15. Thu HN, Eriksson B, Khanh TT, et al. Breastfeeding practices in urban and rural Vietnam:BMC Public Health. 2012;12(1):964.

16. Heck KE, Braveman P, Cubbin C, et al. Socioeconomic status and breastfeeding initiation among California mothers: Public Health Rep. 2006;121(1):51-59.

17. Mulatu A, Tefera B, Aletyework M, et al. Predictors of Optimal Breastfeeding Practices Among Mothers Who Have Less Than 24 Months of Age Children in Misha District, Hadiya Zone, South Ethiopia:Journal of Pregnancy and Child Health. 2015;2(4):1-7.

18. Lessen R, Crivelli-Kovach A. Prediction of initiation and duration of breast- feeding for neonates admitted to the neonatal intensive care unit: $J$ Perinat Neonatal Nurs. 2007;21:256-266.

19. Rajan L. The impact of obstetric procedure and analgesia/anaesthesia during labour and delivery on breastfeeding. Midwife. 1994;10(2):87103.
20. Awi DD, Alikor EA. Barriers to timely initiation of breastfeeding among mothers of healthy full-term babies who deliver at the University of Port Harcourt Teaching Hospital: Niger J Clin Pract . 2006;9(1):57-64.

21. Prez-Escamilla R, Maulen-Radovan I, Dewey KG. The association between cesarean delivery and breast-feeding outcomes among Mexican women.Am J Public Health. 1996;86(6):832-836.

22. Simopoulos AP, Grave GD. Factors Associated with the Choice and Duration of Infant-Feeding Practice. Pediatrics. 1984;74(4):603-614.

23. Engebretsen IMS, Wamani H, Karamagi C, et al. Low adherence to exclusive breastfeeding in Eastern Uganda: A community-based crosssectional study comparing dietary recall since birth with 24 -hour recall. BMC Pediatrics. 2007;7:1-10.

24. Bloss E, Wainaina F, Bailey RC. Prevalence and Predictors of Underweight, Stunting, and Wasting among Children Aged 5 and Under in Western Kenya. Journal of Tropical Pediatrics. 2004;50(5):260-270.

25. Carvalhaes MAdBL, Parada CMGdL, Costa MPd. Factors associated with exclusive breastfeeding in children under four months old in Botucatu-SP, Brazile. Rev Latino-am Enfermagem. 2007; 15(1):62-69.

26. Brunken GS, Silva SM, França GVA, et al. Risk factors for early interruption of exclusive breastfeeding and late introduction of complementary foods among infants in midwestern Brazil. Jornal de Pediatria. 2006;82(6):445-451

27. Shiva F, Nasiri M. A Study of Feeding Patterns in Young Infants. Journal of Tropical Pediatrics. 2003;49(2):89-92.

28. Parada CMGdL, Carvalhaes MAdBL, Jamas MT. Complementary feeding practices to children during their first year of life. Rev Latinoam Enfermagem. 2007;15(2):282-289.

29. Nwankwo BO, Brieger WR. Exclusive breastfeeding is undermined by use of other liquids in rural Southwestern Nigeria. Journal of Tropical Pediatrics. 2002;48(2):109-112.

30. Senyonga R, Muwonge R, Nankya I. Towards a Better Understanding of Exclusive Breastfeeding in the Era of HIV/AIDS: A Study of Prevalence and Factors Associated with Exclusive Breastfeeding from Birth, in Rakai, Uganda. Journal of Tropical Pediatrics. 2004;50(6):348-353.

31. Ryan AS. The resurgence of breastfeeding in United States. Pediatrics. 1997;99(4):1-12.

32. Sachdev HPS, Mehrptra S. Predictors of exclusive breastfeeding in early infancy: operational implications. Indian Pediatrics. 1995;32(12):1277-1296

33. Chudasama R, Patel P, Kavishwar A. Breastfeeding initiation practice and factors affecting breastfeeding in South Gujarat region of India. The Internet Journal of Family Practice. 2008; 7(2).

34. A U Ukegbu, P O Ukegbu, U U Onyeonoro, et al. Determinants of breastfeeding patterns among mothers in Anambra state, Nigeria. South African Journal of Child Health. 2011;5(4):112-116. 